\title{
Gas Sensing Characteristics of Sb-doped $\mathrm{SnO}_{2}$ Nanofibers
}

\author{
Joong-Ki Choi ${ }^{1}$, In-Sung Hwang1, Sun-Jung Kim¹, Joon-Shik Park², Soon-Sup Park², \\ Ki-Young Dong 3 , Byeong-Kwon Ju³ and Jong-Heun Lee ${ }^{1,+}$
}

\begin{abstract}
Undoped and Sb-doped $\mathrm{SnO}_{2}$ nanofibers were prepared by electrospinning and their responses to $\mathrm{H}_{2}, \mathrm{CO}, \mathrm{CH}_{4}, \mathrm{C}_{3} \mathrm{H}_{8}$, and $\mathrm{C}_{2} \mathrm{H}_{5} \mathrm{OH}$ were measured. In the undoped $\mathrm{SnO}_{2}$ nanofibers, the gas response $\left(\mathrm{R}_{\mathrm{a}} / \mathrm{R}_{\mathrm{g}}, \mathrm{R}_{\mathrm{a}}\right.$ : resistance in air, $\mathrm{R}_{\mathrm{g}}$ : resistance in gas) to $100 \mathrm{ppm} \mathrm{C}_{2} \mathrm{H}_{5} \mathrm{OH}$ was very high(33.9), while that to the other gases ranged from 1.6 to 2.2. By doping with $2.65 \mathrm{wt} \% \mathrm{Sb}$, the response to $100 \mathrm{ppm}_{2} \mathrm{H}_{5} \mathrm{OH}$ was decreased to 4.5 , whereas the response to $\mathrm{H}_{2}$ was increased to 3.0. This demonstrates the possibility of detecting a high $\mathrm{H}_{2}$ concentration with minimum interference from $\mathrm{C}_{2} \mathrm{H}_{5} \mathrm{OH}$ and the potential to control the gas selectivity by $\mathrm{Sb}$ doping.
\end{abstract}

Keywords : Gas Sensors, Electrospinning, Nanofibers; $\mathrm{Sb}_{-} \mathrm{SnO}_{2}$, Selective Detection

\section{INTRODUCTION}

Oxide semiconductor gas sensors give a conductance change according to the chemical interaction between the reducing/oxidizing gases and surface adsorbed species. To enhance the gas response, the particle size needs to be decreased to the thickness level of the electron depletion layer $[1,2]$. However, the strong agglomeration between primary particles often hampers the diffusion of analyte gas toward the entire sensing surface, which decreases the gas response[3,4].

In this respect, the less agglomerated configurations of nanostructures are good gas sensing materials. Among various nanostructures, one-dimensional nanofibers are promising candidates because they provide a high surface area due to the presence of many primary particles within each nanofiber, effective gas diffusion via the less agglomerated nanofiber network, and the short diffusion path in the nanofibers[5]. Moreover, Schottky barriers are formed not only between nanofibers but also between primary particles within the nanofibers. All of these can maximize the gas response.

\footnotetext{
${ }^{1}$ Department of Materials Science and Engineering, Korea University, Seoul 136-713, Korea

${ }^{2}$ Convergence Sensor and Device Research Center, Korea Electronics Technology Institute, Kyung-gi 463-816, Korea

${ }^{3}$ Display and Nanosystem laboratory, college of engineering, Korea University, Seoul 136-713, Korea

+ Corresponding author : jongheun@korea.ac.kr

(Received : Mar. 2, 2010, Revised : Jun. 22, Jul. 9, 2010,

Accepted : Aug. 2, 2010)
}

Electrospinning is a facile chemical route to prepare onedimensional nanofibers on a large scale[6]. Although this process was suggested in the beginning of the $20^{\text {th }}$ century[7], intensive research on the fabrication and applications of electrospun nanofibers has been carried during the recent several years[8]. In particular, the gas sensor is one of the most promising applications for nanofibers. To date, the representative gas sensing materials such as $\mathrm{SnO}_{2}[9], \mathrm{TiO}_{2}$ [10], $\mathrm{ZnO}[11], \mathrm{In}_{2} \mathrm{O}_{3}$ [12], and $\mathrm{WO}_{3}[13]$ have been prepared in the form of nanofibers for sensor applications.

The remaining challenges are the control of selectivity using electrospun nanofibers. It is relatively easy to add various additives in the precursor solution for electrospinning. Thus, the compositional control of nanofibers, the preparation of composite nanofibers, and the addition of catalyst materials can be considered as the effective approaches to improve gas selectivity in the nanofiber-based sensors. In this contribution, undoped and $\mathrm{Sb}$-doped $\mathrm{SnO}_{2}$ nanofibers are prepared via electrospinning and their responses to $\mathrm{H}_{2}, \mathrm{CO}, \mathrm{C}_{3} \mathrm{H}_{8}, \mathrm{CH}_{4}$, and $\mathrm{C}_{2} \mathrm{H}_{5} \mathrm{OH}$ are studied. The main focus of this study is placed on the control of gas selectivity and relative gas response by the compositional manipulation of gas sensing materials.

\section{EXPERIMENTAL}

The experimental procedures are shown in Fig. 1. A 8.5 


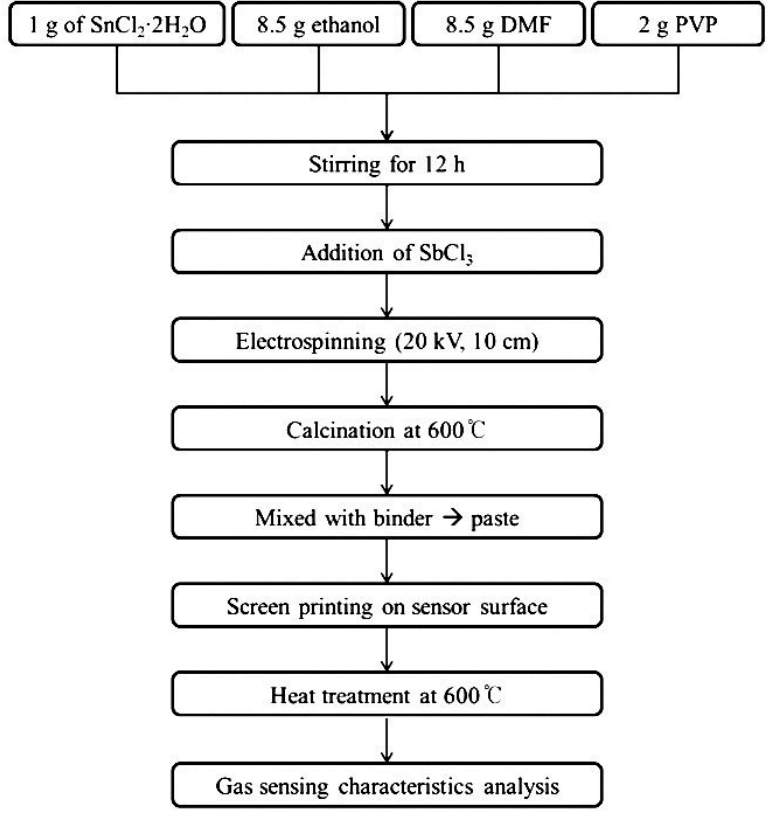

Fig. 1. Schematic diagram of experimental process.

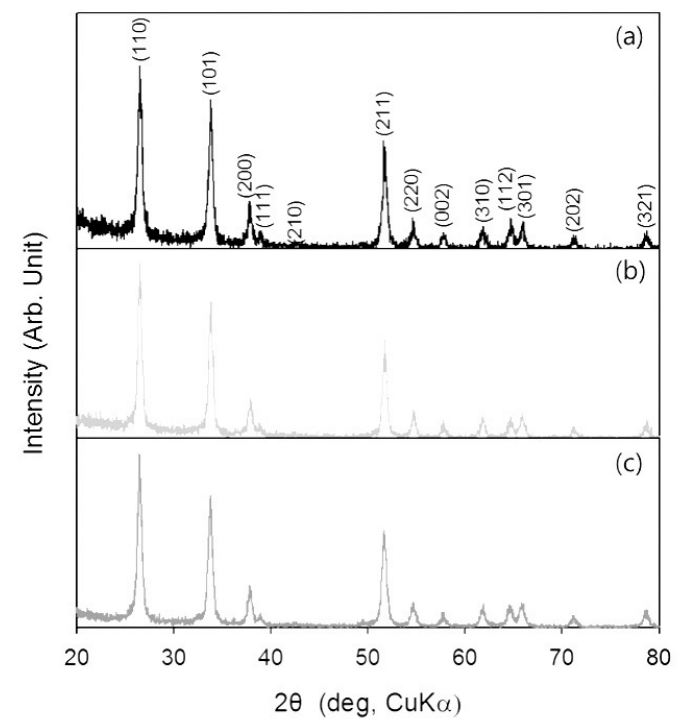

Fig. 2. X-ray diffraction(XRD) patterns of (a) undoped $\mathrm{SnO}_{2}$, (b) $0.88 \mathrm{Sb}-\mathrm{SnO}_{2}$, and (c) $2.65 \mathrm{Sb}-\mathrm{SnO}_{2}$ nanofibers heat-treated at $600^{\circ} \mathrm{C}$ for $2 \mathrm{~h}$.

g of ethyl alcohol(99.9 \%, J. T. Baker Chemical Co., Ltd., USA) was mixed with $8.5 \mathrm{~g}$ of $\mathrm{N}$, N-dimethylformamide (99.5\%, Samchun Chemical Co., Ltd., Korea). Into these mixed solvents was dissolved $1 \mathrm{~g}$ of $\mathrm{SnCl}_{2} \cdot 2 \mathrm{H}_{2} \mathrm{O}(98+\%$, Acros organics, Belgium) and the solution was homogenized for $2 \mathrm{~h}$ by stirring. After the addition of $2 \mathrm{~g}$ of polyvinylpyrroli-done( $\mathrm{Mw}=1,300,000$, Sigma-Aldrich
Co., Ltd., USA), the solution was stirred again for $10 \mathrm{~h}$. This led to a clear Sn-precursor solution for the preparation of $\mathrm{SnO}_{2}$ nanofibers. In order to prepare the $\mathrm{Sb}$-doped $\mathrm{SnO}_{2}$ nanofibers, the corresponding amount of $\mathrm{SbCl}_{3}(98.0 \%$, Kanto Chemical Co., Ltd., Japan) was added to the Snprecursor solution and homogenized for $12 \mathrm{~h}$ by stirring. The doping amount of $\mathrm{Sb}$ was 0.88 or $2.65 \mathrm{wt} \%$ of $\mathrm{SnO}_{2}$. Hereinafter, for simplicity, the $0.88 \mathrm{wt} \% \mathrm{Sb}$-doped and $2.65 \mathrm{wt} \% \mathrm{Sb}$-doped $\mathrm{SnO}_{2}$ nanofibers will be referred as '0.88Sb-SnO ${ }_{2}$ nanofibers' and '2.65 $\mathrm{Sb}^{-\mathrm{SnO}_{2}}$ nano-fibers', respectively.

The precursor solution was loaded in a plastic syringe and electrospun by applying $20 \mathrm{kV}$ at an electrode distance of $10 \mathrm{~cm}$. The as-spun nanofibers were heat-treated at 600 ${ }^{\circ} \mathrm{C}$ for $2 \mathrm{~h}$ to convert the precursor nanofibers into undoped or Sb-doped $\mathrm{SnO}_{2}$ nanofibers. Heat-treated nanofibers were dispersed in isopropanol(99.5 \%, Sigma-Aldrich Co., Ltd., USA) by ultrasonic treatment and subsequently dried at $80{ }^{\circ} \mathrm{C}$ for $24 \mathrm{~h}$. The nanofibers were mixed with organic binders(ethyl cellulose: $\alpha$-terpineol $=1: 14$ by $w t \%$ ) and printed on the $\mathrm{SiO}_{2} / \mathrm{Si}$ substrate with $\mathrm{Pt} / \mathrm{Ti}$ electrode patterns. The sensor was dried at $80{ }^{\circ} \mathrm{C}$ for $2 \mathrm{~h}$ and heattreated again at $600{ }^{\circ} \mathrm{C}$ for $2 \mathrm{~h}$ to decompose the organic contents.

The morphologies of the nanofibers were observed by scanning electron microscopy(SEM, S-4800, Hitachi) and transmission electron microscopy(TEM, FEI Tecnai 20, Philips). The crystal phase was studied using X-ray diffraction(XRD, Rigaku D/MAX-2500). The gas concentration was controlled by changing the mixing ratio of dry parent gases and dry synthetic air. A flow-through technique with a constant flow rate of $500 \mathrm{sccm}$ was used.

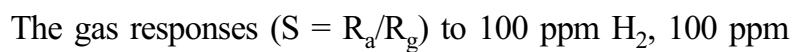
$\mathrm{CO}, 500 \mathrm{ppm} \mathrm{CH}_{4}, 100 \mathrm{ppm} \mathrm{C}_{3} \mathrm{H}_{8}$, and $100 \mathrm{ppm}_{2} \mathrm{H}_{5} \mathrm{OH}$ were measured at $400{ }^{\circ} \mathrm{C}$ by comparing the sensor resistance in air $\left(\mathrm{R}_{\mathrm{a}}\right)$ with that in target gases $\left(\mathrm{R}_{\mathrm{g}}\right)$. The dc 2-probe resistance of the sensor was measured using an electrometer interfaced with a computer.

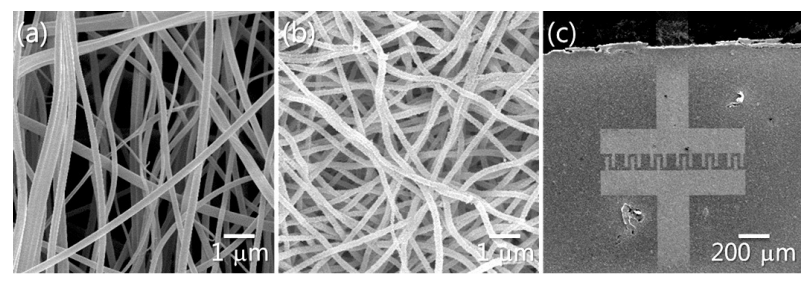

Fig. 3. SEM images of (a) as-spun, Sn-precursor nanofibers, (b) $\mathrm{SnO}_{2}$ nanofibers heat-treated at $600^{\circ} \mathrm{C}$ for $2 \mathrm{~h}$, and (c) $\mathrm{SnO}_{2}$ sensor surface. 


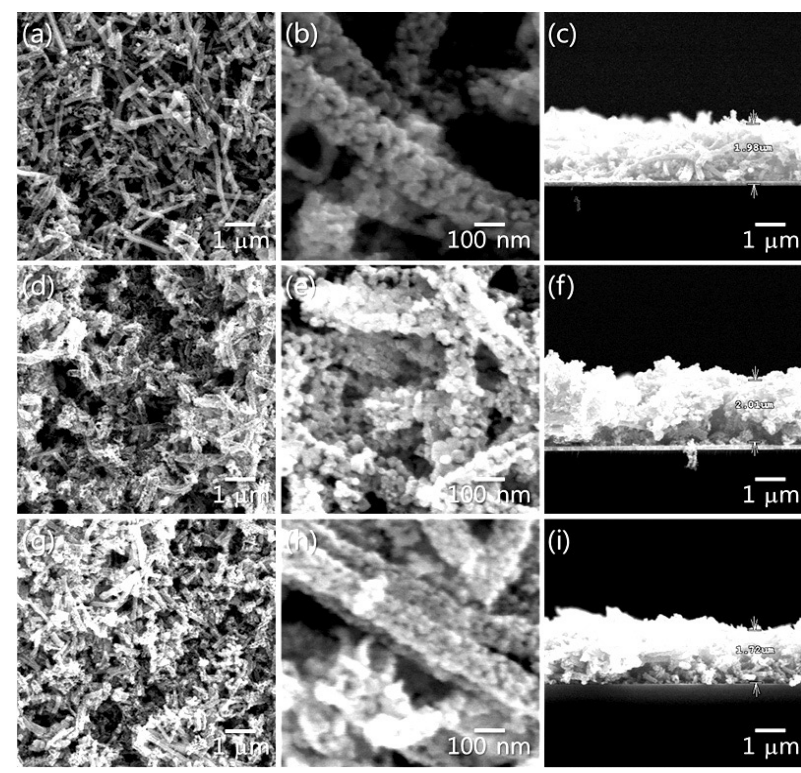

Fig. 4. SEM images of sensor surface: (a-c) undoped $\mathrm{SnO}_{2}$, (d-f) $0.88 \mathrm{Sb}-\mathrm{SnO}_{2}$, and (g-i) $2.65 \mathrm{Sb}-\mathrm{SnO}_{2}$ nanofibers heat-treated at $600^{\circ} \mathrm{C}$ for $2 \mathrm{~h}$.

(a)

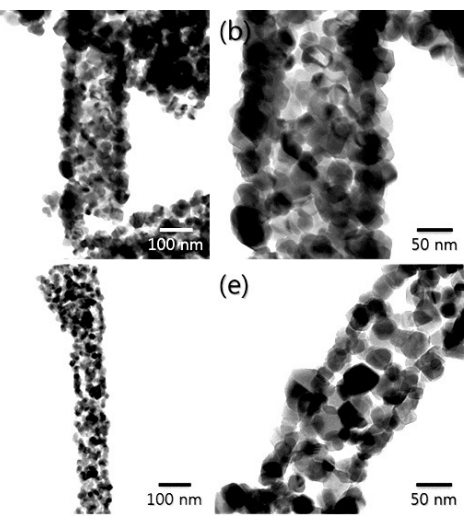

(g)

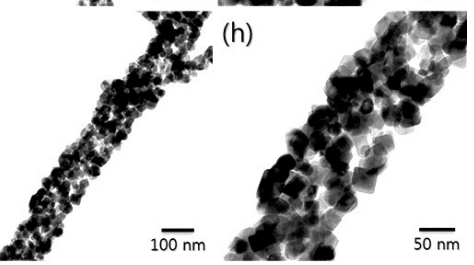

Fig. 5. TEM images of(a), (b) undoped $\mathrm{SnO}_{2}$, (c), (d) $0.88 \mathrm{Sb}-\mathrm{SnO}_{2}$, and (e), (f) $2.65 \mathrm{Sb}-\mathrm{SnO}_{2}$ nanofibers heat-treated at $600{ }^{\circ} \mathrm{C}$ for $2 \mathrm{~h}$.

\section{RESULTS AND DISCUSSION}

\subsection{X-ray diffraction(XRD)}

The undoped $\mathrm{SnO}_{2}$ nanofibers after heat treatment at 600

${ }^{\circ} \mathrm{C}$ for $2 \mathrm{~h}$ were identified as having a rutile structure
(JCPDS \# 77-0447) (Fig. 2a). The $0.88 \mathrm{Sb}-\mathrm{SnO}_{2}$ and 2.65 $\mathrm{Sb}-\mathrm{SnO}_{2}$ nanofibers showed similar XRD patterns (Fig. $2 \mathrm{~b}$ and $2 \mathrm{c}$ ). The Sb-related phases such as $\mathrm{Sb}, \mathrm{Sb}_{2} \mathrm{O}_{5}$, and $\mathrm{Sb}_{2} \mathrm{O}_{3}$ were not found in the XRD patterns, which indicates that $\mathrm{Sb}$ is incorporated into the $\mathrm{SnO}_{2}$ lattice.

\subsection{SEM and TEM analysis}

The as-spun Sn-precursor nanofibers showed clean surface morphology(Fig. 3a) with a diameter ranging from 200 to $300 \mathrm{~nm}$ and a length of several tens of micrometers. The undoped $\mathrm{SnO}_{2}$ nanofibers after heat treatment at $600^{\circ}$ $\mathrm{C}$ for $2 \mathrm{~h}$ showed rougher surface morphology(Fig. 3b). This morphology can be explained by the burn-out of organic content in the Sn-precursor nanofibers. The $\mathrm{SnO}_{2}$ nanofibers were uniformly coated on the surface of the substrates with electrodes(Fig. 3c). The morphologies of the Sb-doped Sn-precursor nanofibers and Sb-doped $\mathrm{SnO}_{2}$ nanofibers were similar to Fig. 3a and $3 b$, respectively(data not shown).

High magnification images of the sensor surfaces are shown in Fig. 4. All the undoped and Sb-doped $\mathrm{SnO}_{2}$ nanofibers on the sensor surface were several micrometers long(Fig. 3a,d,g). This is significantly shorter than the length of the as-spun precursor nanofibers and the heat-treated $\mathrm{SnO}_{2}$ nanofibers(several tens micrometers, for example, as shown in the SEM images in Fig. 3a and 3b), which can be explained by the breaking of the nanofibers during their ultrasonic dispersion. All the nanofibers consisted of small primary particles(Fig. 4b,e,h). The thicknesses of the sensor films determined from the cross-sectional images were $\sim 1.98,2.01$, and $1.72 \mu \mathrm{m}$ for the undoped $\mathrm{SnO}_{2}, 0.88 \mathrm{Sb}-$ $\mathrm{SnO}_{2}$ and $2.65 \mathrm{Sb}-\mathrm{SnO}_{2}$ nanofibers, respectively(Fig. 4c,f,i).

The TEM images of all the specimens showed a bright contrast in the core region(Fig. 5). This indicates the hollow morphology of the undoped $\mathrm{SnO}_{2}, 0.88 \mathrm{Sb}-\mathrm{SnO}_{2}$ and 2.65Sb-SnO $\mathrm{S}_{2}$ nanofibers, which facilitated the diffusion of analyte gases toward the entire sensor surface. In general, hollow nanofibers have been prepared by coaxial twocapillary electrospinning of two immiscible liquids[14,15]. In this study, however, the hollow nanofibers were prepared by single capillary design, which offers the advantage of simplifying the fabrication process. The size of the primary particles within the oxide nanofibers ranged from 20 to $50 \mathrm{~nm}$. 


\subsection{Gas sensing characteristics}

The sensing transients to $100 \mathrm{ppm}_{2}, 100 \mathrm{ppm} \mathrm{CO}, 500$ ppm $\mathrm{CH}_{4}, 100 \mathrm{ppm} \mathrm{C}_{3} \mathrm{H}_{8}$, and $100 \mathrm{ppm}_{2} \mathrm{H}_{5} \mathrm{OH}$ at $400^{\circ}$ $\mathrm{C}$ are shown in Fig. 6. The sensor showed typical n-type semiconductor characteristics, i.e., the resistance was decreased by exposure to the reducing gases. The $\mathrm{R}_{\mathrm{a}}$ value of $\sim 9 \times 10^{6} \Omega$ in the undoped $\mathrm{SnO}_{2}$ nanofiber sensor(Fig. 6a) was decreased to $\sim 8 \times 10^{4} \Omega$ by doping with $0.88 \mathrm{wt} \%$ $\mathrm{Sb}$ (Fig. 6b), and was decreased further to $5 \times 10^{3} \Omega$ by doping with $2.56 \mathrm{wt} \% \mathrm{Sb}$ (Fig. 6c). Babar et al.[16] prepared $\mathrm{Sb}$-doped $\mathrm{SnO}_{2}$ thin films by spray pyrolysis of the solution containing $\mathrm{SnCl}_{4}$ and $\mathrm{SbCl}_{3}$ at $475{ }^{\circ} \mathrm{C}$ and observed that the resistivity of the thin film was decreased as the $\mathrm{Sb}$ doping concentration was increased. The XPS analysis results confirmed the dominance of $\mathrm{Sb}^{5+}$ over $\mathrm{Sb}^{3+}$ and attributed the decrease of resistivity to the increase of electron concentration by the incorporation of $\mathrm{Sb}^{5+}$ ions into $\mathrm{Sn}^{4+}$ sites. Accordingly, the $\mathrm{Sb}$ in this study was thought to exist in the form of $\mathrm{Sb}^{5+}$ rather than $\mathrm{Sb}^{3+}$ and $\mathrm{Sb}^{5+}$ can decrease the resistance by the following reaction[17-19].

$$
\mathrm{Sb}_{2} \mathrm{O}_{5} \stackrel{2 \mathrm{SnO}_{2}}{\longrightarrow} \mathrm{Sb}_{s n}+4 \mathrm{O}^{\circ}+\mathrm{O}_{2}+2 e
$$

The times to reach $90 \%$ variation in resistance upon exposures to gas and air are defined as the $90 \%$ response time $\left(\tau_{\text {res }}\right)$ and $90 \%$ recovery time $\left(\tau_{\text {recov }}\right)$, respectively. The $\tau_{\text {res }}$ values were relatively $\operatorname{short}(0.6 \sim 72.4 \mathrm{~s})$ while the $\tau$ recov values were long $(60.8 \sim 703 \mathrm{~s})$. The short response kinetics implies that the in-diffusion of analyte gas and its oxidation with negatively charged surface oxygen occurred rapidly. Such rapid gas diffusion can also be applied to the in-diffusion of oxygen in the recovery reaction. Thus, the slow recovery suggests that the serial surface reactions

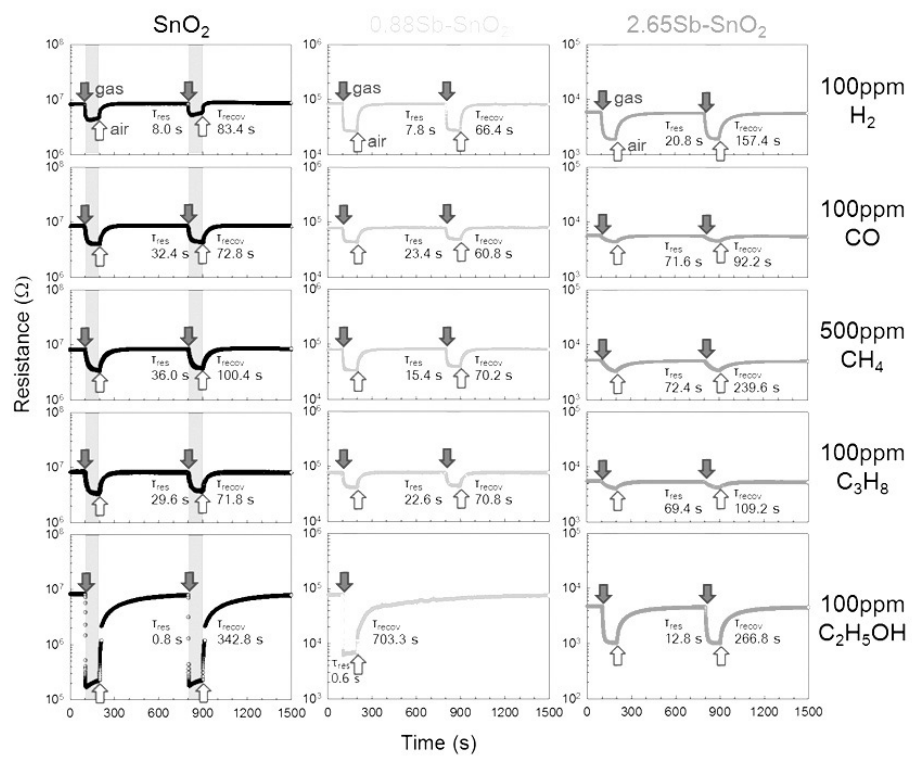

Fig. 6. Dynamic gas sensing transients at $400^{\circ} \mathrm{C}$.

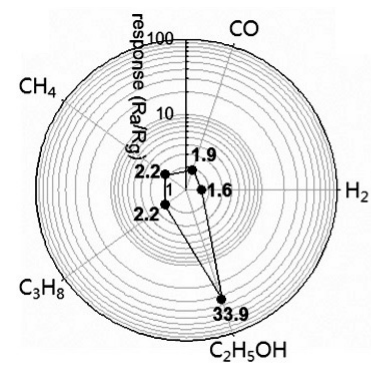

(a)

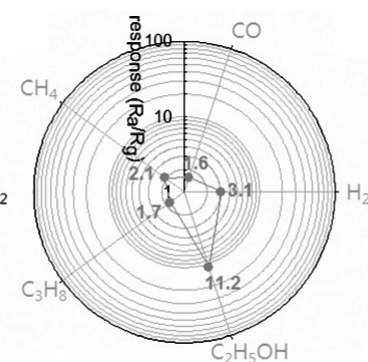

(b)

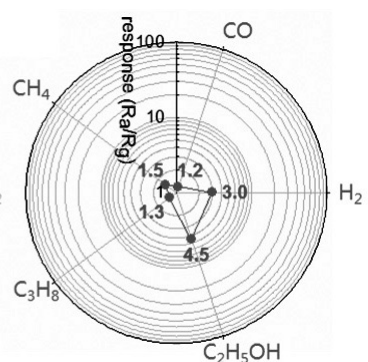

(c)

Fig. 7. Gas responses to $100 \mathrm{ppm}_{2}, 100 \mathrm{ppm} \mathrm{CO}, 500 \mathrm{ppm} \mathrm{CH}_{4}, 100 \mathrm{ppm} \mathrm{C}_{3} \mathrm{H}_{8}$ and $100 \mathrm{ppm} \mathrm{C}_{2} \mathrm{H}_{5} \mathrm{OH}$ of the sensors according to the variation of Sb-doping concentrations: (a) undoped $\mathrm{SnO}_{2}$, (b) $0.88 \mathrm{Sb}-\mathrm{SnO}_{2}$, and (c) $2.65 \mathrm{Sb}-\mathrm{SnO}_{2}$ nanofibers (sensor temperature $=400{ }^{\circ} \mathrm{C}$ ). 
such as adsorption, dissociation, and ionization of oxygen are sluggish.

The responses to $100 \mathrm{ppm}_{2}, 100 \mathrm{ppm} \mathrm{CO}, 500 \mathrm{ppm}$ $\mathrm{CH}_{4}, 100$ ppm $\mathrm{C}_{3} \mathrm{H}_{8}$, and $100 \mathrm{ppm}_{2} \mathrm{H}_{5} \mathrm{OH}$ at $400{ }^{\circ} \mathrm{C}$ are shown as polar plots in Fig. 7. The gas responses were closely dependent upon the Sb doping. As shown in Fig. 7a, the response to $100 \mathrm{ppm} \mathrm{C}_{2} \mathrm{H}_{5} \mathrm{OH}$ was very high(33.9) while that to other gases ranged from 1.6 to 2.2 . This indicates that $\mathrm{C}_{2} \mathrm{H}_{5} \mathrm{OH}$ can be detected in a selective manner using the undoped $\mathrm{SnO}_{2}$ nanofibers. By doping with $0.88 \mathrm{wt} \% \mathrm{Sb}$, the response to $100 \mathrm{ppm}_{2} \mathrm{H}_{5} \mathrm{OH}$ was decreased to 11.2, whereas that to $\mathrm{H}_{2}$ was approximately doubled(3.1). The response to $100 \mathrm{ppm}_{2} \mathrm{H}_{5} \mathrm{OH}$ was further decreased to 4.5 by doping with $2.56 \mathrm{wt} \% \mathrm{Sb}$, whereas the response to $\mathrm{H}_{2}$ remained similar(3.0). Thus, increasing $\mathrm{Sb}$ doping concentration facilitates the detection of a high $\mathrm{H}_{2}$ concentration(for example $>200 \mathrm{ppm}$ ) with minimum interference from $\mathrm{C}_{2} \mathrm{H}_{5} \mathrm{OH}$. Moreover, the different sensing pattern to various gases can be used in artificial olfaction for the recognition and quantization of gases.

\subsection{Discussion}

The sensing of $\mathrm{C}_{2} \mathrm{H}_{5} \mathrm{OH}$ is closely dependent upon the acid-base properties of the sensing materials[20,21].

$$
\begin{aligned}
& \mathrm{C}_{2} \mathrm{H}_{5} \mathrm{OH}(\mathrm{g}) \rightarrow \mathrm{CH}_{3} \mathrm{CHO}(\mathrm{g})+\mathrm{H}_{2}(\mathrm{~g}) \text { (for basic oxide) (2) } \\
& \mathrm{C}_{2} \mathrm{H}_{5} \mathrm{OH}(\mathrm{g}) \rightarrow \mathrm{C}_{2} \mathrm{H}_{4}(\mathrm{~g})+\mathrm{H}_{2} \mathrm{O}(\mathrm{g}) \text { (for acidic oxide) (3) }
\end{aligned}
$$

For the oxidation reaction, $\mathrm{CH}_{3} \mathrm{CHO}+\mathrm{H}_{2}$ consumes more surface oxygens with negative charge than $\mathrm{C}_{2} \mathrm{H}_{4}+$ $\mathrm{H}_{2} \mathrm{O}$. Moreover, the oxidization of chemically stable $\mathrm{C}_{2} \mathrm{H}_{4}$ into $\mathrm{CO}_{2}$ and $\mathrm{H}_{2} \mathrm{O}$ is difficult. Thus, the addition of basic oxides such as $\mathrm{La}_{2} \mathrm{O}_{3}, \mathrm{Sm}_{2} \mathrm{O}_{3}$ and $\mathrm{Gd}_{2} \mathrm{O}_{3}$ is known to enhance the response to $\mathrm{C}_{2} \mathrm{H}_{5} \mathrm{OH}$ significantly[20,22]. The greater electronegativity of $\mathrm{Sb}(2.05)$ than that of $\mathrm{Sn}$ (1.96) means that $\mathrm{Sb}$ is more acidic. Therefore, the decrease of response to $\mathrm{C}_{2} \mathrm{H}_{5} \mathrm{OH}$ by $\mathrm{Sb}$ doping can be explained by the promotion of reaction (3) rather than reaction (2).

Zima et al.[23] reported that the doping of $\mathrm{SnO}_{2}$ with $\mathrm{Sb}$ significantly enhances the response to $\mathrm{H}_{2}$, which is consistent with the present results. This again suggests that the $\mathrm{H}_{2}$ sensing reaction is promoted by the catalytic activity of $\mathrm{Sb}$. This is feasible considering that $\mathrm{Sb}$ is one of the important catalytic materials for the oxidation reaction[24, 25]. Thus, Sb doping can be used as an effective additive to enhance the response to $\mathrm{H}_{2}$ while suppressing the response to $\mathrm{C}_{2} \mathrm{H}_{5} \mathrm{OH}$.

\section{CONCLUSION}

Undoped and $\mathrm{Sb}$-doped $\mathrm{SnO}_{2}$ nanofibers were prepared by electrospinning and their sensing characteristics to $\mathrm{H}_{2}$, $\mathrm{CO}, \mathrm{CH}_{4}, \mathrm{C}_{3} \mathrm{H}_{8}$ and $\mathrm{C}_{2} \mathrm{H}_{5} \mathrm{OH}$ were investigated. The undoped $\mathrm{SnO}_{2}$ nanofibers demonstrated the selective detection of $\mathrm{C}_{2} \mathrm{H}_{5} \mathrm{OH}$. As the $\mathrm{Sb}$ doping concentration was increased to $2.65 \mathrm{wt}^{\%} \%$, the response to $\mathrm{C}_{2} \mathrm{H}_{5} \mathrm{OH}$ was decreased significantly while the response to $\mathrm{H}_{2}$ was enhanced. The effect of $\mathrm{Sb}$ doping concentration on the selectivity was explained by the acid-base properties and catalytic function of $\mathrm{Sb}$.

\section{ACKNOWLEDGMENTS}

This work was supported by Fundamental R\&D program for Core Technology of Materials (M2008 010013) funded by the Ministry of Knowledge Economy.

\section{REFERENCES}

[1] N. Yamazoe, G. Sakai, and K. Shimanoe, "Oxide semiconductor gas sensors”, Catal. Surv. Asia, vol. 7, pp. 63-75, 2003.

[2] N. Yamazoe, "New approaches for improving semiconductor gas sensors", Sens. Actuators, B, vol. 5, pp. 7-19, 1991.

[3] G. Korotcenkov, "Gas response control through structural and chemical modification of metal oxide films: state of the art and approaches", Sens. Actuators, $B$, vol. 107, pp. 209-232, 2005.

[4] D. E. Williams and K. F. E. Pratt, "Microstructure effects on the response of gas-sensitive resistors based on semiconducting oxides", Sens. Actuators, B, vol. 70, pp. 214-221, 2000.

[5] A. Greiner and J. H. Wendorff, "Electrospinning : a fascinating method for the preparation of ultrathin fibers", Angew. Chem. Int. Ed., vol. 46, pp. 5670-5703, 2007.

[6] D. Li and Y. Xia, "Electrospinning of nanofibers: reinventing the wheel", Adv. Mater., vol. 16, pp. 11511170, 2004.

[7] D. H. Reneker and I.-S. Chun, "Nanometre diameter fibers of polymer, produced by electrospinning", Nanotechnology, vol. 7, pp. 216-223, 1996.

[8] W. E. Teo and S. Ramakrishna, "A review on 
electrospinning design and nanofibre assemblies", Nanotechnology, vol. 17, pp. R89-R106, 2006.

[9] Y. Zhang, X. He, J. Li, Z. Miao and F. Huang, "Fabrication and ethanol-sensing properties of micro gas sensor based on electrospun $\mathrm{SnO}_{2}$ nanofibers", Sens. Actuators, B, vol. 132, pp. 67-73, 2008.

[10] I.-D. Kim, A. Rothschild, B. H. Lee, D. Y. Kim, S. M. Jo and H. L. Tuller, "Ultrasensitive chemiresistors based on electrospun $\mathrm{TiO}_{2}$ nanofibers", Nano Lett., vol. 6, pp. 2009-2013, 2006.

[11] Z. Zhang, X. Li, C. Wang, L. Wei, Y. Liu, and C. Shao, " $\mathrm{ZnO}$ hollow nanofibers: fabrication from facile single capillary electrospinning and applications in gas sensors", J. Phys. Chem. C, vol. 113, pp. 1939719403, 2009.

[12] W. Zheng, X. Lu, W. Wang, Z. Li, H. Zhang, Y. Wang, Z. Wang, and C. Wang, "A highly sensitive and fast-responding sensor based on electrospun $\mathrm{In}_{2} \mathrm{O}_{3}$ nanofibers", Sens. Actuators, B, vol. 142, pp. 61-65, 2009.

[13] G. Wang, Y. Ji, X. Huang, X. Yang, P. Gouma, and M. Dudley, "Fabrication and characterization of polycrystalline $\mathrm{WO}_{3}$ nanofibers and their application for ammonia sensing", J. Phys. Chem. B, vol. 110, pp. 23777-23782, 2006.

[14] D. Li, Y. Xia, "Direct fabrication of composite and ceramic hollow nanofibers by electrospinning", Nano Lett., vol. 4, pp. 933-938, 2004.

[15] D. Li and J. T. McCann, and Y. Xia, "Use of electrospinning to directly fabricate hollow nanofibers with functionalized inner and outer surfaces", Small, vol. 1, pp. 83-86, 2005.

[16] A. R. Babar, S. S. Shinde, A. V. Moholkar, C. H. Bhosale, J. H. Kim, and K. Y. Rajpure, "Structural and optoelectronic properties of antimony incorporated tin oxide thin films", J. Alloys and Compd., vol. 505, pp. 416-422, 2010.
[17] V. Dusastre and D. E. Williams, "Sb(III) as a surface site for water adsorption on $\mathrm{Sb}(\mathrm{Sb}) \mathrm{O}_{2}$, and its effect on catalytic activity and sensor behavior", J. Phys. Chem. $B$, vol. 102, pp. 6732-6737, 1998.

[18] Q. Wan and T. H. Wang, "Single-crystalline Sbdoped $\mathrm{SnO}_{2}$ nanowires: synthesis and gas sensor application”, Chem. Comm., pp. 3841-3843, 2005.

[19] A. A. Zhukova, M. N. Rumyantseva, A. M. Abakumov, J. Arbiol, L. Calvo, and A. M. Gaskov, "Influence of antimony doping on structure and conductivity of tin oxide whiskers", Thin Solid Films, vol. 518, pp. 1359-1362, 2009.

[20] T. Jinkawa, G. Sakai, J. Tamaki, N. Miura, and N. Yamazoe, "Relationshio between ethanol gas sensitivity and surface catalytic property of tin oxide sensors modified with acidic or basic oxides", J. Mol. Catal. A: Chem., vol. 155, pp. 193-200, 2000.

[21] S.-J. Kim, P.-S. Cho, J.-H. Lee, C.-Y. Kang, J.-S. Kim, and S.-J. Yoon, "Preparation of multicompositional gas sensing films by combinatorial solution deposition”, Ceram. Int., vol. 34, pp. 827831,2008 .

[22] T. Maekawa, J. Tamaki, N. Miura, and N. Yamazoe, "Development of $\mathrm{SnO}_{2}$-based ethanol gas sensor", Sens. Actuators, B, vol. 9, pp. 63-69, 1992.

[23] A. Zima, A. Kock, and T. Maier, "In- and Sb-doped tin oxide nanocrystalline films for selective gas sensing", Microelectron. Eng., vol. 87, pp. 1467-1470, 2010.

[24] J.-H. Moon, J.-A. Park, S.-J. Lee, T.-H. Zyung, and I.D. Kim, "Pd-doped $\mathrm{TiO}_{2}$ nanofiber networks for gas sensor applications", Sens. Actuators, B, vol. 149, pp. 301-305, 2010.

[25] L. Liu, C. Guo, S. Li, L. Wang, Q. Dong, and W. Li, "Improved $\mathrm{H}_{2}$ sensing properties of Co-doped $\mathrm{SnO}_{2}$ nanofibers", Sens. Actuators, B, in press, 2010.

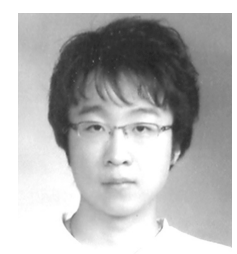

Joong-Ki Choi studied materials science and engineering and received his BS degree from Korea University in 2009. $\mathrm{He}$ is currently a master course student at Korea University. His research topic is oxide nanofiber gas sensors.

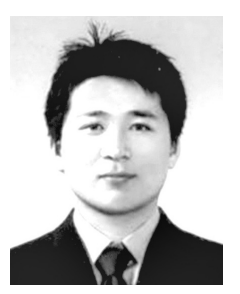

In-Sung Hwang studied materials science and engineering and received his B.S. from Kumoh National University, Korea, in 2004. In 2006, he received his M.S. degree from Korea University. He is currently studying for a Ph.D. at Korea University. His research interest is oxide nanostructure based electronic devices. 


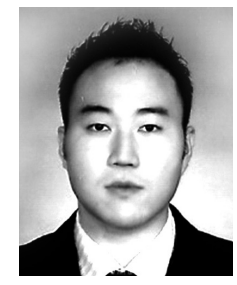

Sun-Jung Kim studied Materials Science and Engineering and received his BS and MS degrees in 2006 and 2008, respectively, at Korea University in Korea. He is currently studying for $\mathrm{PhD}$ degree at Korea University. His research interests are oxide nanostructures for chemical sensor applications and the combinatorial design of gas sensing materials.

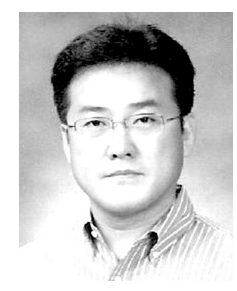

Soon-Sup Park received the Ph.D. degree in material science, from the KAIST in 1992. He is the director in the Environmental Device \& Application Research Center, Korea Electronics Technology Institute (KETI). His current research interests include integrated optical bio-sensors based on a waveguide.

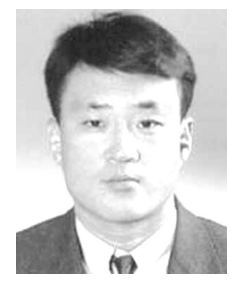

Byeong-Kwon Ju received the Ph.D. in semiconductor engineering from Korea University in 1995. From 1988, he joined the Korea Institute of Science and Technology (KIST), Seoul, where he was engaged in development of mainly flat panel display and MEMS technology as a principal research scientist. In 1996, he spent 6 months as a visiting research fellow at Microele-ctronics Centre, University of South Australia, Australia. Since 2005, he has been a associate professor of Dept. EE of Korea University with his main interest in flexible electronics (OLED, OTFT), field emission devices, Si-micromachining and carbon nanotube-based nano systems. And also he is a program director of National Research Lab.(Display and Nanosystem Lab.) supported by Korean government. Prof. Ju is a member of Society for Information Display(SID), Korea Institute of Electrical Engineering (KIEE), and Korea Sensor Society.

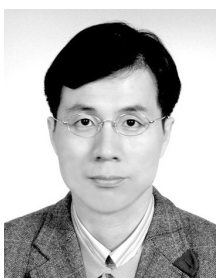

Joon-Shik Park received his BS, MS, and $\mathrm{PhD}$ degrees in Materials Science and Engineering from Hanyang University, Seoul, Korea in 1992, 1994 , and 2004, respectively. Since 1994, he has been doing research in the Korea Electronic Technology Institute (KETI). Currently, he is a principal researcher at the Environmental Device \& Application Research Center of KETI. His current research interests include nanowires, micro chemical and bio sensors, and MEMS standardization.

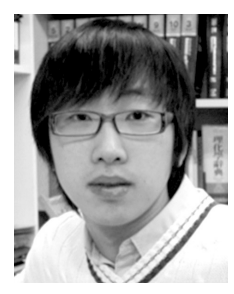

Ki-Young Dong received his MS degree at Korea University in 2009. Currently, he is a Ph.D. candidate in the Department of Electrical Engineering, Korea University. His current research interests include micro-nano electromechanical systems (M-NEMS) and patterning techniques for nano-devices.

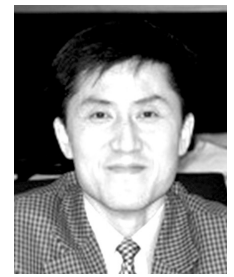

Jong-Heun Lee joined the Department of Materials Science and Engineering at Korea University as an associate professor in 2003, where he is currently professor. He received his B.S., M.S., and Ph.D. degrees from Seoul National University in 1987, 1989, and 1993, respectively. Between 1993 and 1999, he developed automotive air-fuel-ratio sensors at the Samsung Advanced Institute of Technology. He was a Science and Technology Agency (STA) of Japan fellow at the National Institute for Research in Inorganic Materials (currently NIMS, Japan) from 1999 to 2000 and a research professor at Seoul National University from 2000 to 2003. His current research interests include chemical sensors, functional nanostructures, and solid oxide electrolytes. 